\title{
Ecophysiological and morphological parameters related to survival in grass species exposed to an extreme climatic event
}

\author{
Ann Milbau ${ }^{a}$, Liesbeth Scheerlinck ${ }^{a}$, Dirk Reheul ${ }^{b}$, Benny De Cauwer ${ }^{b}$ and Ivan Nijs ${ }^{a, *}$ \\ ${ }^{a}$ Research Group of Plant and Vegetation Ecology, Department of Biology, University of Antwerp, Universiteitsplein 1, B-2610 Wilrijk, Belgium \\ ${ }^{b}$ Department of Plant Production, Faculty of Agricultural and Applied Biological Sciences, Ghent University, Coupure Links 653, B-9000 Ghent, \\ Belgium
}

\author{
Correspondence \\ *Corresponding author, \\ e-mail: ivan.nijs@ua.ac.be \\ Received 21 June 2005; revised 15 August \\ 2005
}

doi: 10.1111/j.1399-3054.2005.00586.x

\begin{abstract}
An experiment was performed to elucidate interspecific differences in survival time of grass species subjected to an extreme climatic event. We exposed eight grass species to a simulated heat wave in the field ('free air' temperature increase at $11^{\circ} \mathrm{C}$ above ambient) combined with drought. We determined whether interspecific differences in survival time were related to the responses of the species to the imposed stress or could be explained by their ecophysiological or morphological characteristics in unstressed conditions. Surprisingly, there was no effect of specific leaf area, but species with a higher total leaf area survived longer. This may arise from a greater water reserve in the plant as a whole, which could delay the desiccation of the meristem, or from reduced evaporation due to a higher leaf area index. Species in which the decrease in light-saturated stomatal conductance $\left(g_{s}\right)$ and photosynthetic $\mathrm{CO}_{2}$ uptake rate $\left(A_{\max }\right)$ was strongly related to the decrease in soil water availability (measured as soil relative water content and stress duration) survived longer than species in which $g_{s}$ and $A_{\max }$ likewise declined but responded more to daily fluctuations in irradiance, temperature, and vapor pressure deficit during the heat wave. We, therefore, hypothesize that interspecific differences in stress survival time might be related to the extent to which stomata react to changes in soil water conditions relatively to changes in other environmental and physiological factors. The results suggest that resistance to extremes is governed by other mechanisms than resistance to moderate drought.
\end{abstract}

\section{Introduction}

Climate-change models predict increases in daily and seasonal temperature variation in addition to changes in mean temperatures (IPCC 2001, Wagner 1996). This will yield more extremes (Easterling et al. 2000, Meehl et al. 2000), such as severe heat waves, which may exert

\footnotetext{
Abbreviations - $A_{\text {max }}$ light-saturated leaf photosynthetic $\mathrm{CO}_{2}$ uptake rate $\left(\mu \mathrm{mol} \mathrm{CO}_{2} \mathrm{~m}^{-2} \mathrm{~s}^{-1}\right) ; C_{i}$, intercellular $\mathrm{CO}_{2}$ concentration ( $\mu \mathrm{mol} \mathrm{CO}_{2} \mathrm{~mol}^{-1}$ ); $F_{O}$, ground fluorescence of the dark-adapted leaf; $F_{m}$, maximum fluorescence of the darkadapted leaf; $F_{v} / F_{m}$, predawn potential quantum yield of photosystem (PS) II $\left(F_{v}=F_{m}-F_{o}\right) ; g_{s}$, light-saturated stomatal conductance $\left(\mathrm{mol} \mathrm{m} \mathrm{m}^{-2} \mathrm{~s}^{-1}\right)$; PPFD, photosynthetic photon flux density $(\lambda=400-700 \mathrm{~nm})\left(\mu \mathrm{mol}\right.$ photons $\left.\mathrm{m}^{-2} \mathrm{~s}^{-1}\right) ; \Psi_{\mathrm{l}}$, predawn leaf water potential (MPa); $\mathrm{RWC}_{\text {soil, }}$ soil relative water content; SLA, specific leaf area (leaf area: leaf dry mass) $\left(\mathrm{m}^{2} \mathrm{~kg}^{-1}\right)$; TR, leaf transpiration rate $\left(\mathrm{mmol} \mathrm{H}_{2} \mathrm{O} \mathrm{m} \mathrm{m}^{-2} \mathrm{~s}^{-1}\right)$; VPD, atmospheric vapor pressure deficit ( $\left.\mathrm{kPa}\right)$; WUE, water use efficiency of photosynthesis $\left(\mathrm{CO}_{2}\right.$ fixed per unit water transpired) ( $\left.\mathrm{mmol} \mathrm{mol}^{-1}\right)$.
} 
major effects on the distribution of plant species and the composition of plant communities, e.g. by debilitating established plants or by creating gaps through plant mortality (Buckland et al. 2001, Solomon and Kirilenko 1997, Stampfli and Zeiter 2004).

A lot of research has been done on the responses to moderate drought and heat, but until now, there are only a handful of studies in which plants are exposed to the lethal stress levels experienced during extreme events. This is the case despite the fact that extremes play a disproportionate role in shaping the physiology, ecology, and evolution of organisms (Gaines and Denny 1993, Gutschick and BassiriRad 2003). Moreover, most of these studies have focused on community processes (e.g. recolonization, competition, invasion, the balance between $\mathrm{C}_{3}$ and $\mathrm{C}_{4}$ species, and the role of species richness during extreme events) (Buckland et al. 1997, Musil et al. 2005, Stampfli and Zeiter 2004, Van Peer et al. 2001, 2004, White et al. $2000,2001)$ rather than on the factors responsible for the different responses of individual species. Also, the combined effect of extreme heat and drought has thus far hardly been studied, especially at the ecophysiological level (Van Peer et al. 2004, Wang and Huang 2004), while water deficits in the field rarely act alone (Chaves et al. 2002).

To help predict future changes in global vegetation patterns, we need more knowledge on the mechanisms underlying interspecific differences in survivorship under extremes and on the ecophysiological basis of the sensitivity to extremes in individual species. Which plant species will be more robust and which are prone to decline in a more extreme, future climate? Simple predictors of survival based on easily measurable plant traits are needed to overcome this.

The current study was aimed at finding ecophysiological and morphological plant parameters that correlated with survival time of grass species exposed to a simulated heat wave combined with drought. Both parameters measured on plants not exposed to the heat wave and responses of plants subjected to the extreme were considered. Eight grass species, known to differ in drought sensitivity, were used, and swards of them were subjected to a 'free air' temperature increase of $11^{\circ} \mathrm{C}$ coinciding with drought. Survival time was derived from exposing the swards to increasing stress duration.

\section{Materials and methods}

\section{Plant material}

Eight perennial $\mathrm{C}_{3}$ grass species, known to differ in drought sensitivity, were monitored for various morphological and ecophysiological parameters both in non-stress conditions and during exposure to a simulated heat wave: Agrostis tenuis Sibth. (At), Arrhenatherum elatius L. (Ae), Cynosurus cristatus L. $(C C)$, Dactylis glomerata L. (Dg), Festuca arundinacea Schreb. (Fa), Festuca rubra L. (Fr), Lolium perenne L. $(L p)$, and Poa trivialis L. (Pt). As a first step towards the understanding of resistance to extremes, we used only species that have many traits in common. Including species belonging to different functional types might blur the underlying mechanisms, because a variety of adaptations and specific defence mechanisms against drought and heat could be introduced. From 1 to 4 April 2003, seeds of the selected species were planted at $2.5 \mathrm{~cm}$ interspaces in plastic containers $(20 \times 15 \times 14.5 \mathrm{~cm}$ deep $)$ to form monocultures of 30 plants each. Monocultures were used instead of individual plants to avoid unrealistic vertical radiation profiles. At every plant position, the first germinating seed out of five was kept.

Before sowing, the containers were weighed empty and then filled with a fixed amount of air-dried steamsterilized sandy loam. Three samples of this air-dried soil were oven-dried at $60^{\circ} \mathrm{C}$ for 10 days and then weighed. Based on the mean ratio of the oven-dried to air-dried mass of these samples, the oven-dried mass of the soil added to the containers was calculated, as a basis for monitoring soil water content (see below). After sowing, the containers were placed in a greenhouse until 27 May and outdoors afterwards. They were well watered until the start of the experiment and were supplied with low amounts of fertilizer (total: $50 \mathrm{~kg} \mathrm{~N} \mathrm{ha}^{-1}$, $50 \mathrm{~kg} \mathrm{~K} \mathrm{ha}^{-1}$, and $80 \mathrm{~kg} \mathrm{P} \mathrm{ha}^{-1}$ ) in two equal fractions on 13 June and 31 July. At the start of the experiment (11 August 2003), the containers were randomly assigned to four identical sets: one unheated set and three heated sets in which the plants were exposed to a simulated heat wave in combination with drought stress. Each set contained six replicate containers of each monoculture species or 48 containers in total. Daily rotation of the containers between the heated sets and within all sets minimized possible effects of set and position. The containers assigned to the unheated set were kept close to field capacity, while irrigation of the containers in the heated sets was arrested on 11 August. Soil relative water content $\left(\mathrm{RWC}_{\text {soil }}\right)$ in these heated containers was calculated daily on nine randomly chosen containers per species by dividing the actual amount of water in the soil (soil mass including water minus mass of oven-dried soil) by the potential amount of water in the soil (mass of fully wet soil after drainage minus that of oven-dried soil). 


\section{Microclimate}

A heat wave ('free air' temperature increase and drought) was simulated by irradiating three replicate sets of 48 containers, placed level with the surrounding grassland vegetation, with additional infrared radiation (IR) $(0.8-3 \mu \mathrm{m})$ using the FATI system (Nijs et al. 1996). Three second-generation prototypes of this device (Van Peer et al. 2004) were used to individually irradiate the three sets that were exposed. Each FATI module consisted of a frame with six 1500-W IR lamps, suspended $1.2 \mathrm{~m}$ above the ground, which homogeneously irradiated an area of $1.2 \times 1.2 \mathrm{~m}$. On a fourth set of 48 containers, which served to measure plant characteristics in non-stress conditions and was not exposed to drought and heat, a dummy construction was placed with lamp enclosures but no IR lamps. The heated sets were covered with a transparent shelter suspended at 2.5-m height, which eliminated precipitation but did not obstruct direct solar radiation. The experiment lasted until all plants in the heated sets had died (8 September). Because a natural heat wave occurred during the stress period, heating was switched off for 3 days (ambient maximum air temperature $\left(\mathrm{T}_{\mathrm{a}}\right)>32^{\circ} \mathrm{C}$ ) to avoid unrealistic stress levels in the heated sets.

In each set, type-T copper constantan thermocouples (Omega Engineering, Stamford, CA) measured air temperature shielded from direct sunlight (centre of the set at 5-cm height), and type-T plug-mounted probes (TM Electronics, Goring, Sussex, UK) measured soil temperature at a depth of $5 \mathrm{~cm}$. Canopy temperature of the whole set of 24 containers was measured with noncontact IR semiconductors with a view angle of $90^{\circ}$ placed at $60-\mathrm{cm}$ height (Stork Intermes, Naarden, the Netherlands) and photosynthetic photon flux density (PPFD) with JYP 1000 gallium arsenide quantum sensors (SDEC, Reignas sur Indre, France). Sensor output was recorded every $10 \mathrm{~min}$ with a DL2e data logger (Delta-T, Burwell, Cambridge, UK).

Average daily maximum, minimum, and mean temperatures [air $\left(T_{a}\right)$, canopy $\left(T_{c}\right)$, and soil $\left(T_{S}\right)$ ] during the stress period are summarized in Table 1 for both the unheated and heated sets. The average instantaneous increase in temperature owing to the heating (days when the heating was switched off excluded) equalled $11.27 \pm \mathrm{SD} 2.15^{\circ} \mathrm{C}, 12.73 \pm \mathrm{SD} 2.43^{\circ} \mathrm{C}$, and $11.79 \pm \mathrm{SD} 2.15^{\circ} \mathrm{C}$ for $\mathrm{T}_{\mathrm{a}}, \mathrm{T}_{\mathrm{C}}$, and $\mathrm{T}_{\mathrm{s}}$, respectively $(\mathrm{n}=600$ in all cases).

\section{Plant measurements}

Measurements were done on the heated plants to detect an ecophysiological basis for resistance to climatic extremes and on plants in the unheated set to determine potential predictors of stress-survival time.

At the beginning of the experiment, six plants per species (one per container) were harvested from the unheated set to determine total leaf area per plant (for each leaf, the area was approximated by multiplying leaf length by average leaf width; precision $0.5 \mathrm{~mm}$ ), number of leaves per plant, total plant leaf mass (after oven-drying for $48 \mathrm{~h}$ at $70^{\circ} \mathrm{C}$ ), and specific leaf area (SLA). Productivity of the monocultures during summer was estimated by cutting two containers (30 plants) per species to $2.5 \mathrm{~cm}$ and harvesting them again after 1 month of regrowth. Biomass was dried for $48 \mathrm{~h}$ at $70^{\circ} \mathrm{C}$.

On the unheated plants, ecophysiological parameters were measured at the start of the heat wave (11 August 2003) and on 22 August 2003, after measurements on the heated plants had been finished. The plants in the heated sets were measured daily during the stress period [except predawn leaf water potential $\left(\Psi_{1}\right)$, which was measured every two days] until the leaves were desiccated and ecophysiological measurements were no longer possible (after about 10 days of stress). For all measurements, each day the plants were randomly chosen, with the constraint of taking an equal number of plants per set, each from a different container. Plants near the container edge were avoided. All measurements were done on recently expanded leaves.

$\Psi_{\text {I }}$ was measured on six excised leaves per species with a Scholander pressure chamber (ARIMAD-2, ARI Kfar Charuv Water Supply Accessories, Tel Aviv, Israel). Leaves were cut before sunrise, enclosed in plastic bags during transport to the nearby lab, and measured immediately. Instantaneous determinations of light-saturated photosynthetic rate $\left(A_{\max }\right)$, stomatal conductance $\left(g_{s}\right)$,

Table 1. Average values \pm SD of daily maximum, minimum, and mean temperatures (air, canopy, and soil at 5-cm depth) during a simulated heat wave (11 August-6 September 2003) for unheated and heated plants.

\begin{tabular}{|c|c|c|c|c|c|c|c|c|c|}
\hline & \multicolumn{3}{|c|}{ Air temperature $\left({ }^{\circ} \mathrm{C}\right)$} & \multicolumn{3}{|c|}{ Canopy temperature $\left({ }^{\circ} \mathrm{C}\right)$} & \multicolumn{3}{|c|}{ Soil temperature $\left({ }^{\circ} \mathrm{C}\right)$} \\
\hline & Maximum & Minimum & Mean & Maximum & Minimum & Mean & Maximum & Minimum & Mean \\
\hline Unheated ( $n=27$ ) & $25.4 \pm 3.6$ & $13.3 \pm 2.7$ & $18.5 \pm 2.5$ & $25.7 \pm 4.1$ & $11.7 \pm 3.0$ & $17.8 \pm 2.9$ & $20.7 \pm 2.3$ & $16.0 \pm 2.4$ & $18.4 \pm 2.2$ \\
\hline Heated $(n=27)$ & $35.8 \pm 3.6$ & $23.7 \pm 2.1$ & $28.8 \pm 2.2$ & $36.5 \pm 3.6$ & $23.9 \pm 2.8$ & $29.3 \pm 2.5$ & $32.6 \pm 2.5$ & $26.0 \pm 2.2$ & $29.2 \pm 2.0$ \\
\hline
\end{tabular}


transpiration rate (TR), and intercellular $\mathrm{CO}_{2}$ concentration $\left(C_{i}\right)$ at saturating PPFD $\left(1500 \mu \mathrm{mol}\right.$ photons $\left.\mathrm{m}^{-2} \mathrm{~s}^{-1}\right)$ were done around midday with a portable gas exchange system (LI-6400, Li-Cor, Inc. Lincoln, NE) on six leaves per species. $\mathrm{CO}_{2}$ concentration, air temperature, and humidity during the measurements approximated the ambient conditions. Instantaneous water use efficiency of photosynthesis (WUE) was calculated as $A_{\max }$ TR. Chlorophyll fluorescence parameters were measured around noon using a portable chlorophyll fluorometer (nine replicates per species; PEA, Plant Efficiency Analyser, Hansatech Instruments Ltd, Norfolk, UK). The background fluorescence signal $\left(F_{O}\right)$ and the maximum fluorescence $\left(F_{m}\right)$ were measured following dark adaptation for $1 \mathrm{~h}$ (leaf clips) to determine the maximum quantum efficiency of PSII $\left[F_{v} / F_{m}=\left(F_{m}-F_{0}\right) / F_{m}\right]$.

Survival time of the stressed plants was measured by removing each time two containers per species $(=60$ plants) from below the FATI constructions, after different exposure times to the heat wave $(6,11,15,17,19,22$, 24,26 , and 29 days of stress). These containers were then rewatered, and the number of individuals that restarted to grow was counted. The drought periods required to reduce survivorship to 50 and $25 \%$ ( $T_{50}$ and $T_{25}$, respectively) were used as measures of survival time.

\section{Results}

\section{Survival}

The survival curves of the eight species were significantly different (survival analysis, Wilcoxon test, $\left.\chi_{7,0.05}^{2}=165.95, \quad P<0.0001\right)$. Percentage survival decreased sharply after around 8 days of stress in the species $A t$ and $C C$ and between days 10 and 14 in the others (Fig. 1A). Species Ae and Dg survived the longest, with live individuals still being found after 19 and 22 days of stress, respectively. The ranking according to decreasing $T_{50}$ was $D g$, Fa \& Fr, Ae, Lp, Pt, CC, At. According to decreasing $T_{25}$, only the position of $A e$ changed: Ae, Dg, Fa \& Fr, Lp, Pt, Cc, At.

\section{Responses of the parameters to the progressive heat and drought}

$\mathrm{RWC}_{\text {soil }}$ decreased progressively during the stress period and reached a minimum after 8 to 10 days, depending on the species (Fig. 1B). Monocultures of At depleted the water supply fastest, whereas $\mathrm{RWC}_{\text {soil }}$ remained highest in the monocultures of $A e$ and $F r . \Psi_{1}$ declined sharply in all species after about 3 days (Fig. 2). After 7 days, the values had dropped below the maximum range of the equipment of $-3 \mathrm{MPa}$. Ae had the highest average $\Psi_{1}$ during the first 7 days and $A t$ the lowest, but interspecific differences were limited. In all species, $F_{v} /$ $F_{m}$ fluctuated around 0.8 at the beginning of the stress and then decreased, indicating photoinhibition (Fig. 2). In $A e$, however, there was little decline throughout. Most species were able to recover partially at around days 6-7, which were overcast, except for $A t$, in which $F_{v} / F_{m}$ declined from day 4 onwards.

Fig. 3 shows the progressive effect of drought and heat on $g_{s}$ and $A_{\max }$, which followed a similar pattern

A

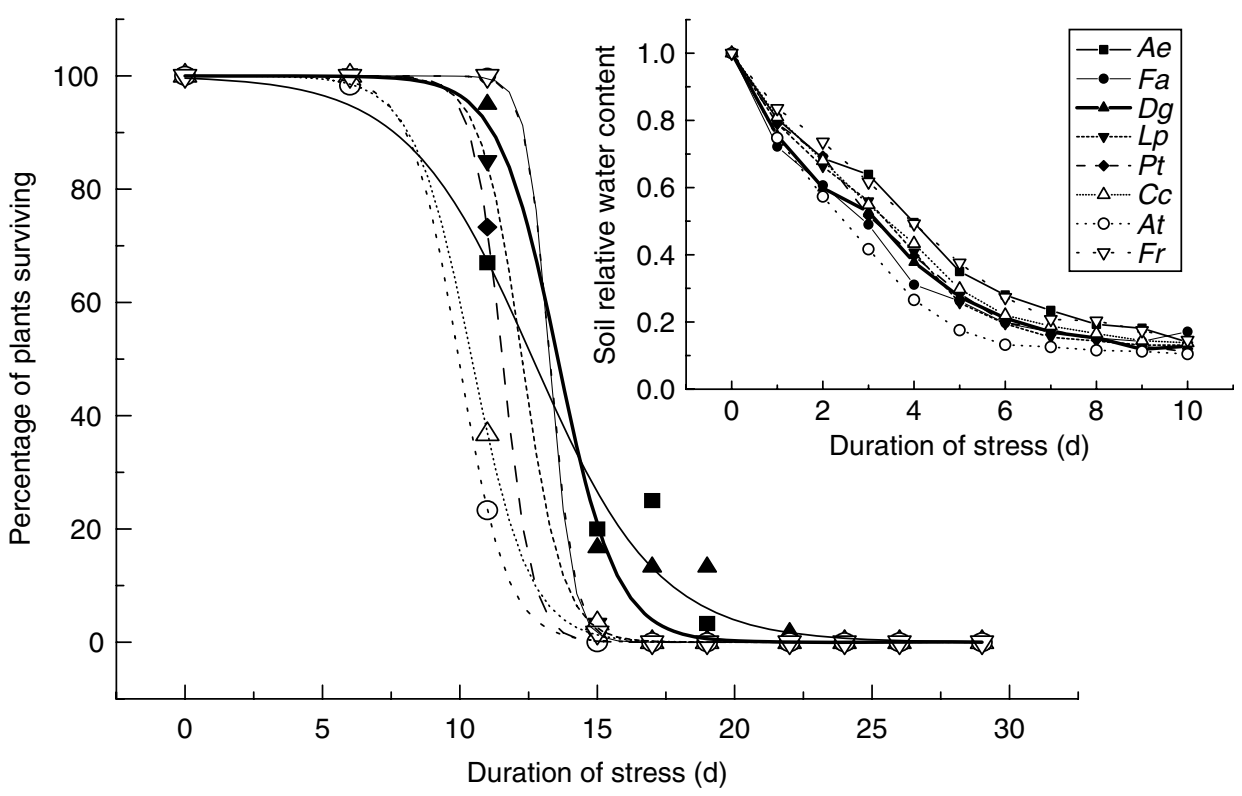

Fig. 1. (A) Species-survival percentage measured after different exposure times to a simulated heat wave. Data are fitted with dose-response curves: $y=A /\left[1+10^{\text {(logxo }}\right.$

${ }^{-x) p}$ ]. Each symbol is based on 60 plants in two containers. Note that the $\mathrm{Fa}$ and $\mathrm{Fr}$ curves overlap. (B) Decrease of soil relative water content during the first 10 days of exposure to the heat wave. Data are means of nine containers. Species codes: Ae, Arrhenatherum elatius; At, Agrostis tenuis; Cc, Cynosurus cristatus; Dg, Dactylis glomerata; Fa, Festuca arundinacea; Fr, Festuca rubra; $L p$, Lolium perenne; Pt, Poa trivialis. 


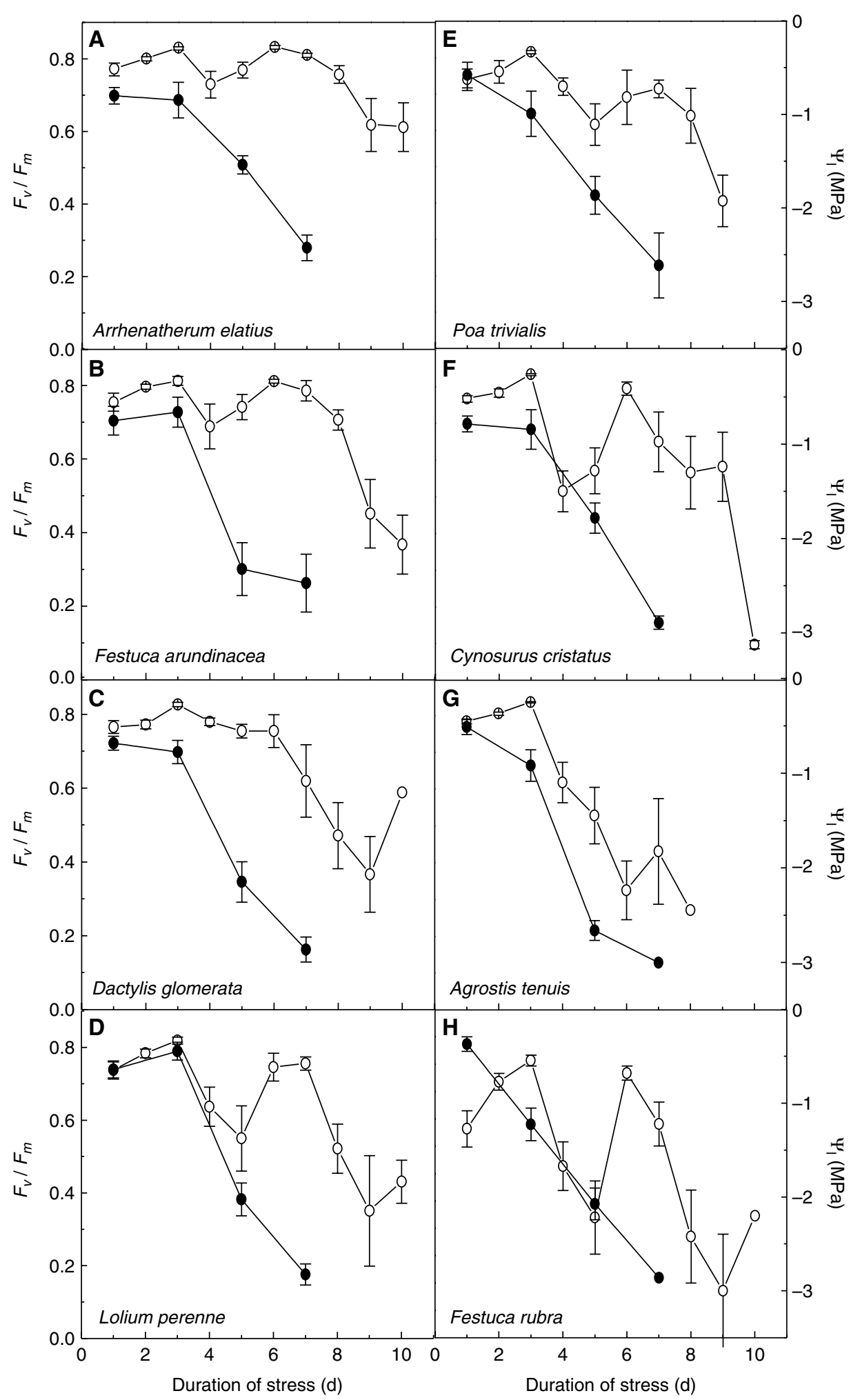

Fig. 2. Time course of maximum quantum yield of photosystem II $\left(F_{v} / F_{m}\right)$ (open circles) and predawn leaf water potential $\left(\Psi_{l}\right)$ (solid circles) during the heat wave. Means \pm SE of nine and six replicates, respectively.

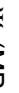

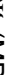

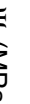

and approximated zero after 10 days of stress. Along with the decline, there were a lot of daily fluctuations in both parameters, except in the species with low values
(Ae and $D g$ ). These fluctuations were most probably due to variation in irradiance, temperature, and atmospheric vapor pressure deficit (VPD) between the days. The 


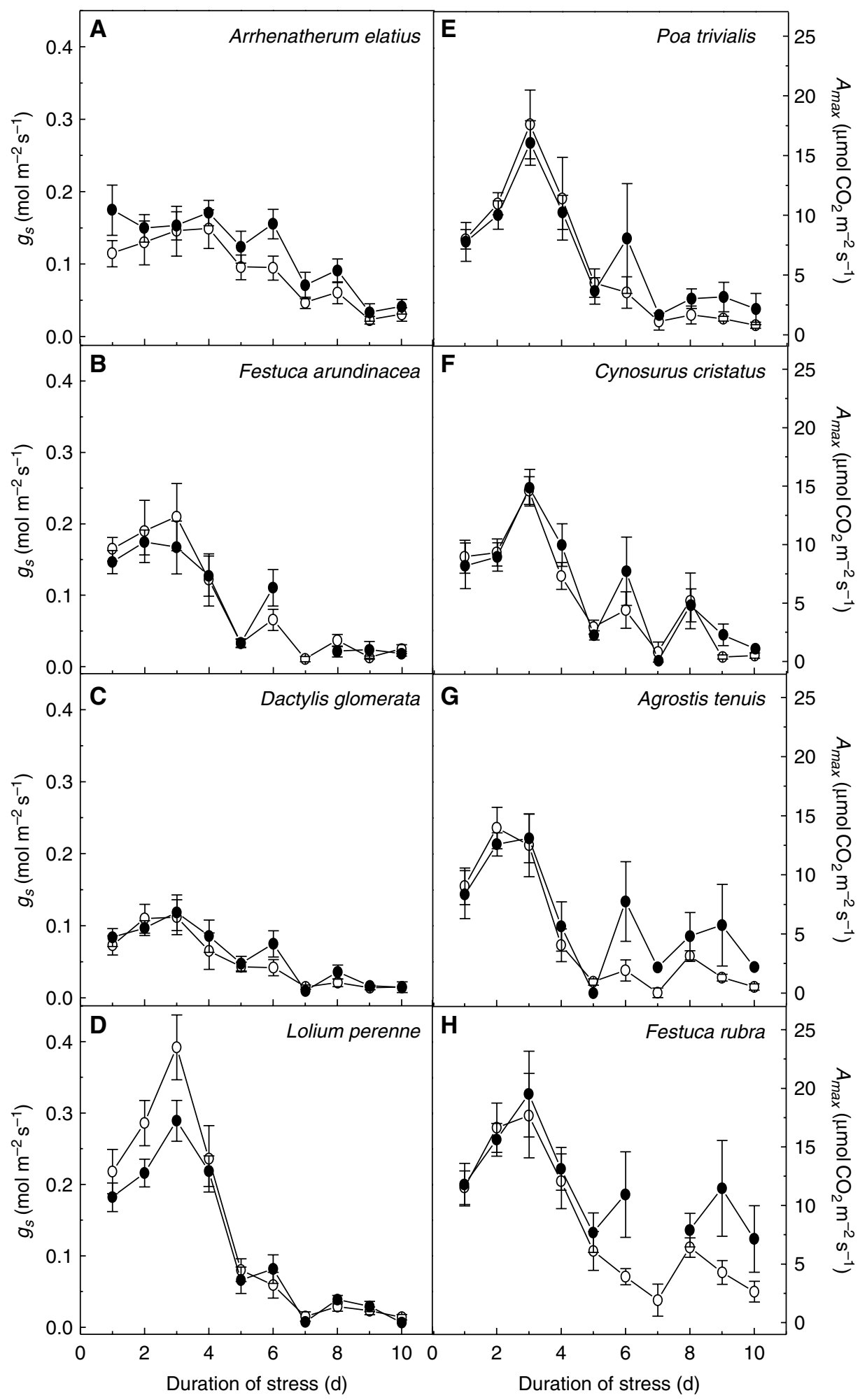

Fig. 3. Time course of lightsaturated stomatal conductance $\left(g_{s}\right)$ (open circles) and photosynthetic $\mathrm{CO}_{2}$ uptake rate $\left(A_{\max }\right)$ (solid circles) during the heat wave. Means \pm SE of six replicates. 
the first 4 days of stress in all species, but thereafter started to increase (Fig. 4). Ae, Dg, and Fa maintained low values of $C_{i}$ longer than the other species.

\section{Relationship between ecophysiological responses during the stress and survival time}

We investigated whether species-survival time was related to the course of the ecophysiological parameters during the stress. First, for every parameter, we calculated the average value by species during the first 10 days of exposure and tested whether these averages explained a significant fraction of the interspecific variation in survival time (linear regressions). Only the parameters related to the maintenance of photosynthetic capacity, $F_{v} / F_{m} \quad\left(T_{25}=-1.108+21.607 \times F_{v} / F_{m,} \quad P=0.028\right.$, $\left.r^{2}=0.58\right)\left(\right.$ Fig. 5A), and $C_{i}\left(\mathrm{~T}_{25}=19.923-0.019 \times C_{i}\right.$, $P=0.018, r^{2}=0.63$ ) (Fig. 5B) were significantly related to survival time. Having a high or a low value of $A_{\max } g_{s}$

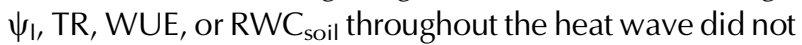
determine survival time.

In a second analysis, $A_{\max }, g_{s}$ and TR were linearly regressed against exposure time, for each species separately. This enabled us to quantify how much of the variation in these parameters was explained by stress duration (by means of $r^{2}$ ) and how much variation was due to other factors, such as daily fluctuations in temperature, VPD, irradiation, etc. $\left(1-r^{2}\right)$. Because there were only four measurements of $\psi_{1}$ during the stress, this parameter was not considered. All regressions were significant, except $A_{\max }$ against time for species $\mathrm{Fr}$ $(P=0.066)$. We subsequently tested whether the obtained $r^{2}$ values and slopes of the significant regressions were associated with species-survival time. A significant relationship was found between survival time and $r^{2}$ of the relationship between $g_{s}$ and stress duration $\left[\mathrm{T}_{25}=1.750+21.410 \times r^{2}\right.$ (gs against stress duration), $P=0.004, r^{2}=0.78$ ] (Fig. 5C). The $r^{2}$ of the relationship between $A_{\max }$ and stress duration also explained survival time $\left[\mathrm{T}_{25}=4.582+12.766 \times r^{2}\left(A_{\max }\right.\right.$ against stress duration), $P=0.009, r^{2}=0.78$ ] (Fig. 5D). The slopes of the aforementioned regressions were not related to survival time.

In a third analysis, the above regressions by species of $A_{\text {max }} g_{s}$ and TR were repeated, but this time against $\mathrm{RWC}_{\text {soil }}$ instead of against stress duration, to quantify how much of the variability in these parameters was accounted for by the water availability in the soil. All the regressions were significant, except for $A_{\max }$ against $\mathrm{RWC}_{\text {soil }}$ in $\operatorname{Fr}(P=0.061)$. A significant relationship was found only between species-survival time and the $r^{2}$ of $A_{\text {max }}$ against $\mathrm{RWC}_{\text {soil }}\left[\mathrm{T}_{50}=4.393+13.026 \times r^{2}\left(A_{\max }\right.\right.$ against $\left.R W C_{\text {soil }}\right), P=0.006, r^{2}=0.81$ ] (Fig. 5E).

\section{Prediction of survival time from plant parameters in non-stress conditions}

Fig. 6 shows the interspecific variation in morphological and ecophysiological parameters in non-stress conditions. As there was a clear range in most parameters (except in $F_{v}$ / $F_{m i}$ not shown), we investigated whether speciessurvival time could be predicted from them. Linear regressions with survival time $\left(T_{25}\right.$ or $\left.T_{50}\right)$ as dependent variable and the average values of the species characteristics

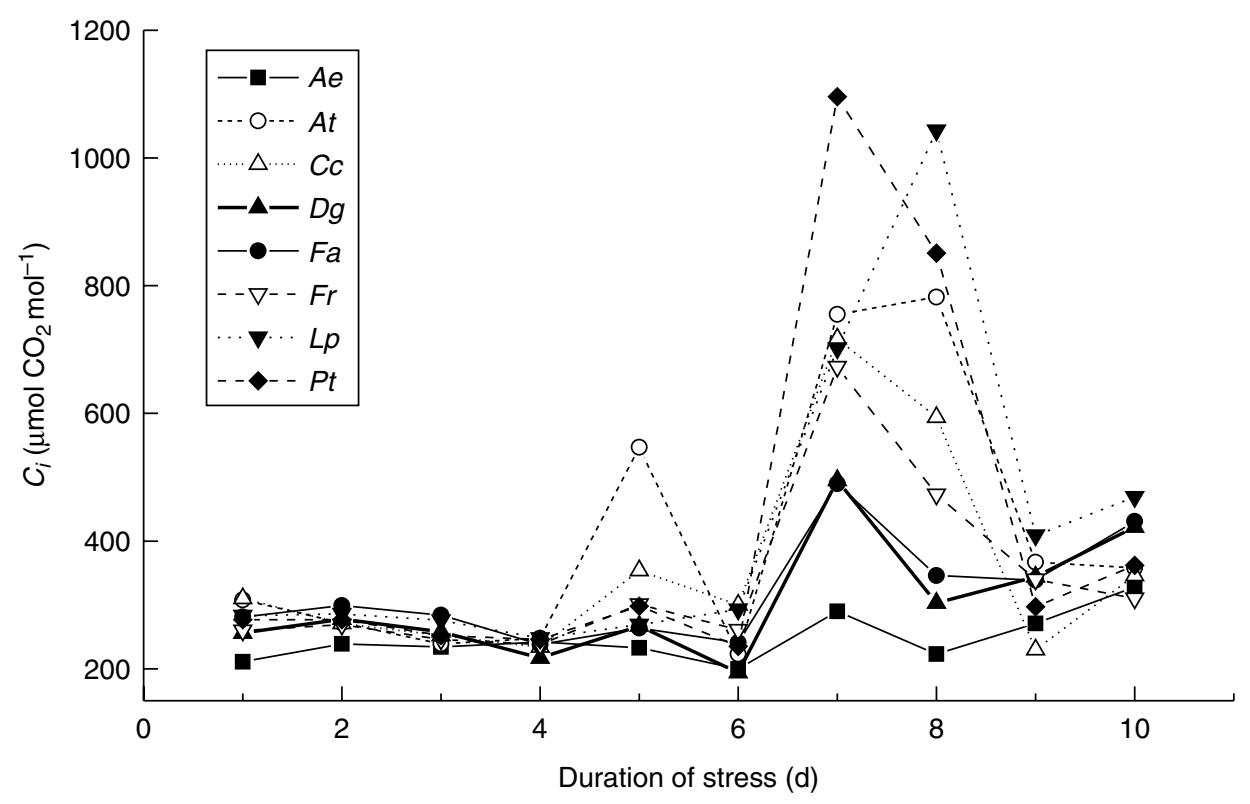

Fig. 4. Time course of intercellular $\mathrm{CO}_{2}$ concentration $\left(C_{i}\right)$ during the heat wave. Data are means of six replicates. See Fig. 1 for species codes. 

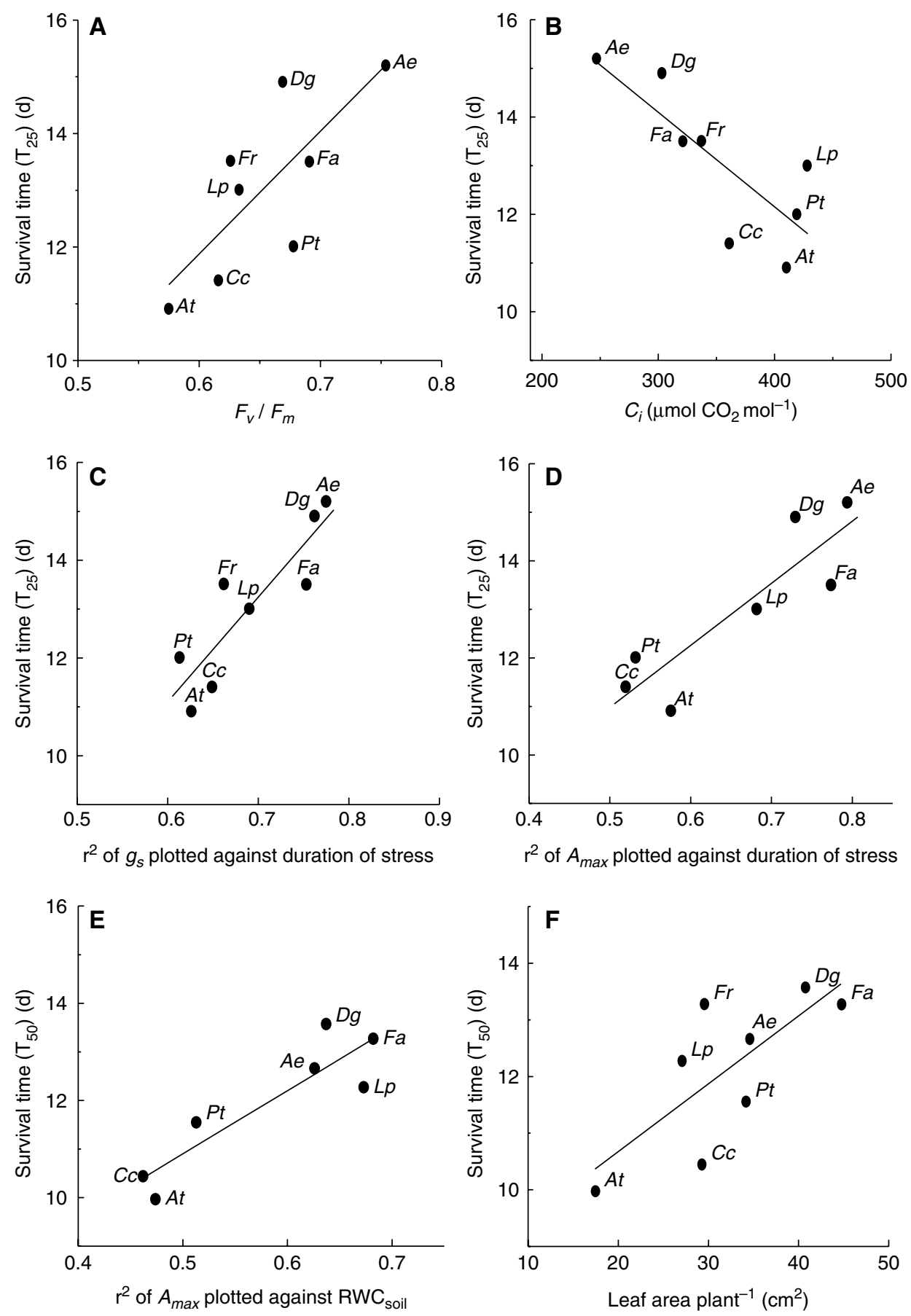

Fig. 5. Relationship between species-survival time and (A) maximum quantum yield of photosystem II $\left(F_{v} / F_{m}\right)$, (B) intercellular $\mathrm{CO}_{2}$ concentration $\left(C_{i}\right)$, (C) $r^{2}$ of the regression between light-saturated stomatal conductance $\left(g_{s}\right)$ and time, indicating the amount of variation in $g_{s}$ explained by stress duration, (D) $r^{2}$ of the regression between light-saturated photosynthetic $\mathrm{CO}_{2}$ uptake rate $\left(A_{\text {max }}\right)$ and time, indicating the amount of variation in $A_{\max }$ explained by stress duration, (E) $r^{2}$ of the regression between $A_{\max }$ and soil relative water content ( $R W C_{\text {soil }}$ ), indicating the amount of variation in $\mathrm{A}_{\text {max }}$ explained by $R W C_{\text {soil, }}(F)$ total leaf area per plant $(n=6)$. $\ln (\mathrm{A})$ and $(\mathrm{B}), \mathrm{x}$-values are averages per species during the first 10 days of stress. In (D) and (E), there is no data point for $\mathrm{Fr}$, because regressions of $A_{\max }$ against time or $\mathrm{RWC}_{\text {soil }}$ were not significant in this species. Survival times $T_{50}$ and $T_{25}$ are the drought periods required to reduce survivorship to $50 \%$ and $25 \%$, respectively. See Fig. 1 for species codes. (measured on unheated plants) as independent variables revealed a significant relationship for leaf area per plant: survival time was longer in plants with a greater total leaf area $\left[\mathrm{T}_{50}=8.265+0.120 \times\right.$ (leaf area per plant), $\left.P=0.033, r^{2}=0.56\right]$ (Fig. 5F). None of the other parameters were related to survival time, although the species that survived longest, Ae and $D g$, had low values of $A_{\text {max }}, g_{s,}$ and TR and a high WUE compared with the other species.

\section{Discussion}

\section{Relationship between ecophysiological responses during the stress and survival time}

Although high averages of $A_{\max }, g_{s}$ and TR during the stress might indicate high water use, these values were not related to survival time. The reason for this 
A

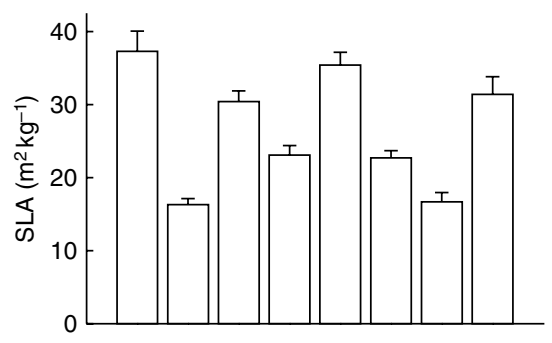

D
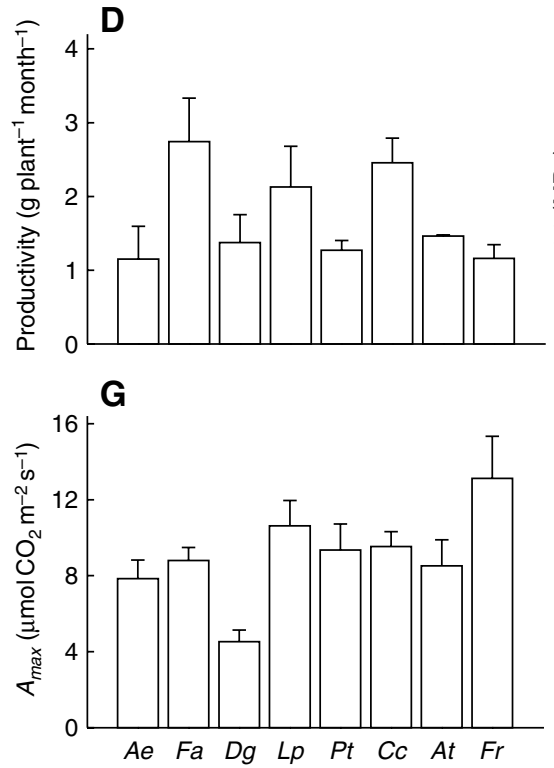

B

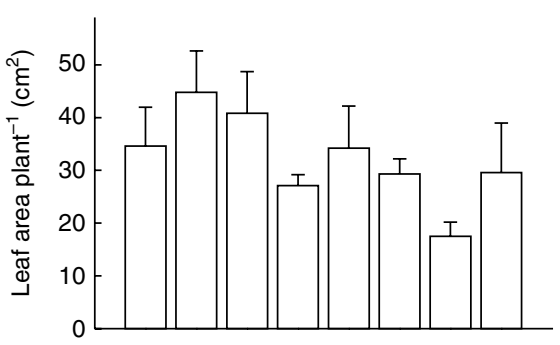

E
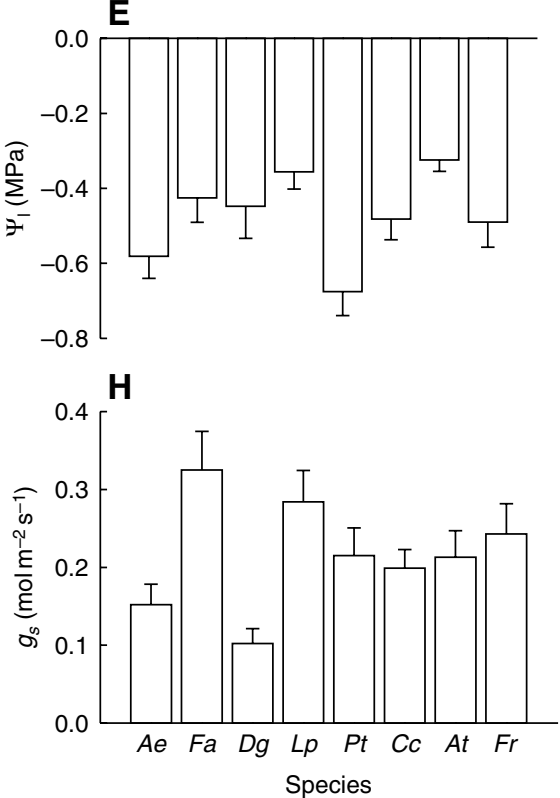

C
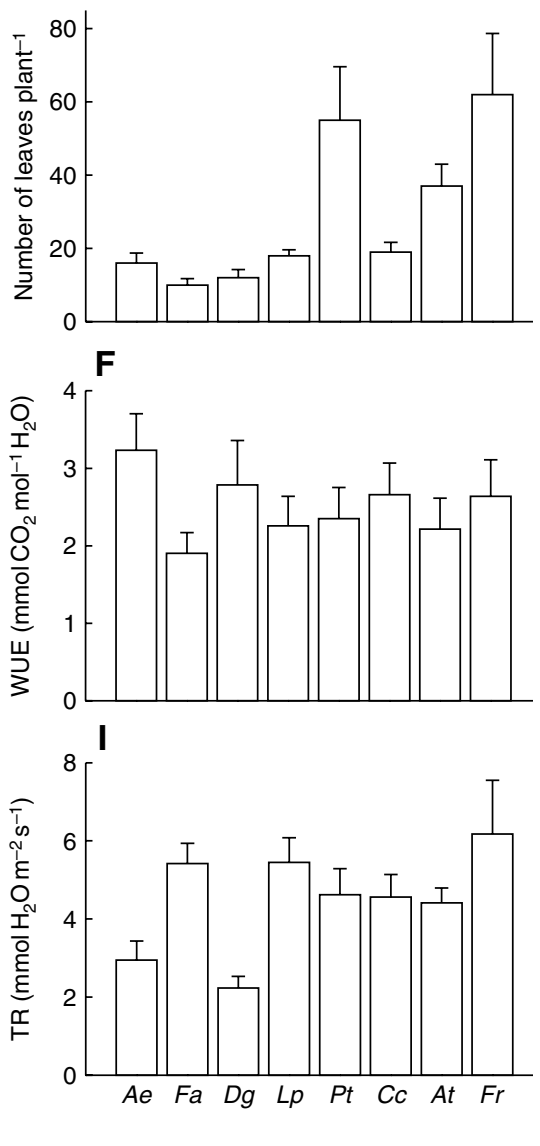

Fig. 6. Plant characteristics of the grass species measured in unstressed conditions (not exposed to the heat wave and well watered). Means \pm sE of six replicates for specific leaf area (SLA), total leaf area per plant, and number of leaves per plant, and means \pm SE of 12 replicates for water use efficiency (WUE), predawn leaf water potential $\left(\psi_{1}\right)$, light-saturated photosynthetic $\mathrm{CO}_{2}$ uptake rate $\left(A_{\text {max }}\right)$, stomatal conductance $\left(g_{s}\right)$, and transpiration rate (TR). Productivity was measured on two containers per species. See Fig. 1 for species codes.

might be that such averages do not distinguish whether a species has a high photosynthetic rate at the beginning of the stress which sharply decreases when water becomes scarce or a moderate initial photosynthetic rate which is maintained throughout the stress period. Therefore, information on how rapidly physiological parameters change with developing stress or on the magnitude of these responses might be more relevant. This was confirmed by our study of the relationship between the ecophysiological parameters and the imposed stress. By quantifying how much of the daily variation in the parameters was accounted for by the progressive drought $\left(r^{2}\right.$ of the regressions), we could explain $78\left(r^{2}\right.$ of $g_{s}$ or $A_{\max }$ against duration of stress) to $81 \%\left(r^{2}\right.$ of $A_{\max }$ against $\left.\mathrm{RWC}_{\text {soil }}\right)$ of the variance in survival time (Fig. 5C,D,E). This suggests that, despite the important role of root parameters (e.g. root biomass, root/shoot ratio) for survival during drought, there might also be an effect of ecophysiological and morphological (see further) factors on the survival of species under extreme climatic events.

Stomatal conductance depends simultaneously on multiple factors such as light, temperature, VPD, intercellular $\mathrm{CO}_{2}$ concentration, guard cell and epidermal turgor, and water flow through the soil and plant (Franks et al. 2001, Netting 2000, Tuzet et al. 2003). The degree to which these factors influence $g_{s}$ varies between species (Tardieu and Simonneau 1998). For example, stomata of different species vary in their sensitivity to leaf water potential (Henson et al. 1989, Leuning et al. 2003, Tuzet et al. 2003), which in turn is a function of soil water potential, the rate of flow through the soil and plant, and the xylem hydraulic resistance. In our data, we found interspecific differences in the amounts of daily variation in $g_{s}$ and $A_{\max }$ that were explained by 
stress duration or $\mathrm{RWC}_{\text {soil, }}$ which were indicators for water availability of the soil. In the best-surviving species (Ae and $D g$ ), $g_{s}$ and $A_{\max }$ correlated strongly with the decreasing soil water supply, while only little daily variation in these parameters could be attributed to other factors. In the other species, the dependence of $g_{s}$ and $A_{\max }$ on stress duration was lower, which suggests that the stomata in these species were more influenced by the aforementioned microclimatic factors. Much higher peaks in the values of $g_{s}$ and $A_{\max }$ in these species compared with $A e$ and $D g$ at days 3 and 6 (when there was a significant drop in PPFD, air temperature, and VPD; data not shown) support this (Fig. 3). We therefore hypothesize that interspecific differences in stress-survival time might be related to the extent to which stomata react to changes in soil water conditions relatively to changes in other environmental and physiological factors. The reason why this has an effect on survival time is that peak values in $g_{s}$ and $A_{\max }$ are not immediately compensated by equally large drops in these parameters, such that after a few days of stress the consumed amount of water is greater in the species with higher fluctuations, although their average values of $g_{s}$ and $A_{\max }$ might be comparable with less fluctuating species. A similar division of stomatal responses is mentioned in a study of Gutschick and Simonneau (2002), who state that stomatal conductance responds to two distinct environments: (1) the local and aerial environment of the leaf, defined by irradiance, temperature, humidity, $\mathrm{CO}_{2}$ concentration, and boundary-layer condition and (2) the distal environment, particularly that of the roots, which generates root-sourced signals of water stress [abscisic acid (ABA)] and contributes to determining leaf water potential. However, more research on the relative importance of aerial vs. root signals $(A B A)$ for reducing $g_{s}$, with respect to survival of extremes, is needed.

Species that maintained high values of $F_{v} / F_{m}$ (around 0.8 ) (Figs 2 and $5 \mathrm{~A}$ ) and low values of $C_{i}$ (around $260 \mu \mathrm{mol} \mathrm{CO}_{2} \mathrm{~mol}^{-1}$ ) (Figs 4 and $5 \mathrm{~B}$ ) during the stress survived longer. This was not surprising, because both parameters are related to the condition of the photosynthetic apparatus (electron transport capacity, reflected in $F_{v} / F_{m}$, and carboxylation capacity, reflected in $\left.C_{i}\right)$, which is a good proxy for overall stress level (Srivastava et al. 1995). These parameters therefore rather indicate symptoms of drought injury than mechanisms of tolerance. An increase in $C_{i}$ when stress becomes severe often indicates non-stomatal limitations to photosynthesis, involving progressive downregulation or inhibition of metabolic processes (Flexas and Medrano 2002, Lawlor 1995). However, caution must be taken, because $C_{i}$ calculation under drought might be inaccurate, because patchy stomatal closure and changes in mesophyll conductance to $\mathrm{CO}_{2}$ often tend to overestimate $C_{i}$ (Bota et al. 2004, Buckley et al. 1997).

Although only eight grass species were used, a range in survival times and different responses to the stress were observed. When more species and functional types are considered, the diversity of plant responses, special adaptations, and specific defence mechanisms against extreme heat and drought is likely to further increase (Chaves et al. 2002). The use of species belonging to the same functional type, however, has the advantage that underlying mechanisms might be easier to detect, because interference of different mechanisms is limited. Even though our results apply only to the studied grass species, we believe that the detected relationships might also be relevant for other species, because increasing water loss due to fluctuations in $g_{s}$ might adversely affect all species under progressive drought stress.

In this experiment, we chose to do the gas exchange and fluorescence measurements around midday, because we wanted to compare the species at the moment when they suffered the most from the imposed stress. Differences between the species might, however, be more pronounced when fluorescence measurements are done predawn to remove the effect of preillumination and when gas exchange measurements are done before noon, because at midday, photosynthetic depression may occur. Future research may reveal whether the results might be improved by measuring the optimal physiological status of plants during a heat wave instead of midday values of gas exchange. As the plants in this study had no stress history, acclimation to stress as a result of previous exposure was not considered. Exposure to subsequent stress episodes can influence the stomatal reaction to $\Psi_{1}, V P D$, irradiance, etc. in a way that water loss is scaled down (Bohnert and Sheveleva 1998, Tabaei-Aghdaei et al. 2000); hence, the survival times recorded in the current study may well represent a lower limit for the stress levels used.

\section{Relationship between survival time and plant characteristics in non-stress conditions}

Total leaf area per plant was the only morphological characteristic related to survival time, with longer survival in species with more foliage (Fig. 5F). This was surprising, because a greater transpiring surface evidently enhances water loss, and many plant species react to drought by partial or complete abscission of the leaves (Clifton-Brown et al. 2002, Rascher et al. 2004, San Jose et al. 2003). The above finding is also 
in contradiction with the idea that slow growth enhances resistance to moderate drought (Polley et al. 2002, Tardieu and Simonneau 1998).

However, when due to extreme conditions the stomata are almost entirely closed, plants with a large leaf area might have a greater water reserve, which will be depleted first before the basal meristem desiccates, and the plant eventually dies. This might explain the longer survival time in the grasses with a larger leaf area. Whether this mechanism occurs also in other life forms remains to be seen, although it would not be unexpected to find it in other hemicryptofytes than grasses. Another possible explanation is the relatively high leaf area index (LAI) in species with a high leaf area per plant. The leaf area in the studied species ranged from 18 to $45 \mathrm{~cm}^{2}$, and the area per plant in the containers was approximately $10 \mathrm{~cm}^{2}$. This produces a LAI between 1.8 and 4.5 depending on the species. Because a canopy with a LAI of 4.5 is relatively dense, this may produce a boundary layer of still air reducing evaporation and conserving water in the species with a higher total leaf area. There was no correlation between SLA and survival, although a low SLA is often associated with plants developed under conditions of poor water supply (Fernández et al. 2002). Resistance to extremes thus seems to be governed by other mechanisms than resistance to moderate drought.

None of the ecophysiological plant characteristics measured on the unheated plants were related to stress-survival time; the main reason for this being that the behavior in unheated conditions was a poor predictor of the behavior during the heat wave. For example, while most species reduced $g_{s}$ by a factor of two in response to the stress, the most 'water wasting' species in non-limiting conditions $(\mathrm{Fa})$ reduced $g_{s}$ by a factor of four, which made it the second-most economic species when water was scarce.

\section{Conclusions}

Our data showed that species in which $g_{s}$ and $A_{\max }$ were strongly related to soil water availability (reflected by stress duration and $\mathrm{RWC}_{\text {soil }}$ ) were able to survive longer in conditions of intense, progressive drought combined with extreme elevated temperatures. In contrast, species in which $g_{s}$ and $A_{\max }$ likewise declined but responded relatively more to the daily fluctuations in irradiance, temperature, and VPD during the heat wave died sooner, probably because they had consumed more water during the first days of the stress during which they showed high peaks in $g_{s}$ and $A_{\max }$. Maintenance of photosynthetic capacity, demonstrated by a high average value of $F_{v} / F_{m}$ and a low value of $C_{i}$ during the first 10 days of stress, was also associated with long survival. The most surprising result of our experiment, however, was the positive relationship between leaf area per plant and survival time and the lack of an effect of SLA. These results suggest that survival of extreme climatic events may rely on specific mechanisms that have received little attention in ecological stress research thus far. More explicit studies, separating the influences of the local environment of the leaf and the root signals involved in reducing stomatal conductance during severe stress, are needed to further the development of a mechanistic understanding of responses to heat and drought extremes. We suggest that further research should as well test whether our findings apply also to other grass species and to other functional types.

Acknowledgements - This research was supported by the Belgian Federal Science Policy Office, under the programme Global Change, Ecosystems and Biodiversity.

\section{References}

Bohnert HJ, Sheveleva E (1998) Plant stress adaptations making metabolism move. Curr Opin Plant Biol 1: 267-274

Bota J, Medrano H, Flexas J (2004) Is photosynthesis limited by decreased Rubisco activity and RuBP content under progressive water stress? New Phytol 162: 671-681

Buckland SM, Grime JP, Hodgson JG, Thompson K (1997) A comparison of plant responses to the extreme drought of 1995 in northern England. J Ecol 85: 875-882

Buckland SM, Thompson K, Hodgson JG, Grime JP (2001) Grassland invasions: effects of manipulations of climate and management. J Appl Ecol 38: 301-309

Buckley TN, Farquhar GD, Mott KA (1997) Qualitative effects of patchy stomatal conductance distribution features on gas-exchange calculations. Plant Cell Environ 20: $867-880$

Chaves MM, Pereira JS, Maroco J, Rodrigues ML, Ricardo CPP, Osório ML, Carvalho I, Faria T, Pinheiro C (2002) How plants cope with water stress in the field. Photosynthesis and Growth. Ann Bot 89: 907-916

Clifton-Brown JC, Lewandowski I, Bangerth F, Jones MB (2002) Comparative responses to water stress in staygreen, rapid- and slow senescing genotypes of the biomass crop Miscanthus. New Phytol 154: 335-345

Easterling DR, Meehl GA, Parmesan C, Chagnon SA, Karl TR, Mearns LO (2000) Climate extremes: Observations, Modeling, Impacts. Science 289: 2068-2074 
Fernández RJ, Wang M, Reynolds JF (2002) Do morphological changes mediate plant responses to water stress? A steady-state experiment with two $\mathrm{C}_{4}$ grasses. New Phytol 155: 79-88

Flexas J, Medrano H (2002) Drought-inhibition of photosynthesis in $\mathrm{C}_{3}$ plants: stomatal and non-stomatal limitations revisited. Ann Bot 89: 183-189

Franks PJ, Buckley TN, Shope JC, Mott KA (2001) Guard cell volume and pressure measured concurrently by confocal microscopy and the cell pressure probe. Plant Physiol 125: 1577-1584

Gaines SD, Denny MW (1993) The largest, smallest, lowest, longest, and shortest: extremes in ecology. Ecology 74: 1677-1692

Gutschick VP, BassiriRad H (2003) Extreme events as shaping physiology, ecology, and evolution of plants: toward a unified definition and evaluation of their consequences. New Phytol 7: 947-957

Gutschick VP, Simonneau T (2002) Modelling stomatal conductance of field-grown sunflower under varying soil water content and leaf environment: comparison of three models of stomatal response to leaf environment and coupling with an abscisic acid-based model of stomatal response to soil drying. Plant Cell Environ 25: 1423-1434

Henson IE, Jensen CR, Turner NC (1989) Leaf gas exchange and water relations of lupins and wheat. I. Shoot response to soil water deficits. Aust J Plant Physiol 16: 401-413

IPCC (2001) Technical summary of the working group I report. In: Houghton JT, Ding Y, Griggs DJ, Noguer M, Van der Linden PJ, Dai X, Maskell K, Johnson CA (eds) Climate Change 2001: The Scientific Basis. Contribution of Working Group I to the Third Assessment Report of the Intergovernmental Panel on Climate Change. Cambridge University Press, Cambridge, UK, pp 21-83

Lawlor DW (1995) The effects of water deficit on photosynthesis. In Smirnoff N (ed) Environment and Plant Metabolism. Flexibility and Acclimation. BIOS Scientific Publishers, Oxford, UK, pp 129-160

Leuning R, Tuzet A, Perrier A (2003) Stomata as part of the plant-soil-atmosphere continuum. In Menuccini M, Grace J, Moncrieff J, McNaughton K (eds) Forests at the LandAtmosphere Interface. CAB International, Edinburgh, UK, pp 21-83

Meehl GA, Karl T, Easterling DR, Chagnon S, Pielke R, Chagnon D, Evans J, Groisman PY, Knutson TR, Kunkel KE (2000) An introduction to trends in extreme weather and climate events: observations, socioeconomic impacts, terrestrial ecological impacts, and model projections. Bull Am Meteor Soc 81: 413-416

Musil CF, Schmiedel U, Midgley GF (2005) Lethal effects of experimental warming approximating a future climate scenario on southern African quartz-field succulents: a pilot study. New Phytol 165: 539-547
Netting AG (2000) PH, abscisic acid and the integration of metaboloism in plants under stressed and non-stressed conditions: cellular responses to stress and their implication for plant water relations. J Exp Bot 51: 147-158

Nijs I, Kockelbergh F, Teughels H, Blum H, Hendrey G, Impens I (1996) Free air temperature increase (FATI): a new tool to study global warming effects on plants in the field. Plant Cell Environ 19: 495-502

Polley HW, Tischler CR, Johnson HB, Derner JD (2002) Growth rate and survivorship of drought: $\mathrm{CO}_{2}$ effects on the presumed tradeoff in seedlings of five woody legumes. Tree Physiol 22: 383-391

Rascher U, Bobich EG, Lin GH, Walter A, Morris T, Naumann M, Nichol CJ, Pierce D, Bil K, Kudeyarov V, Berry JA (2004) Functional diversity of photosynthesis during drought in a model tropical rainforest - the contributions of leaf area, photosynthetic electron transport and stomatal conductance in net ecosystem carbon exchange. Plant Cell Environ 27: 1239-1256

San Jose JJ, Bracho R, Montes R, Nikonova N (2003) Comparative energy exchange from cowpeas (Vigna unguiculata (L.) Walp cvs. TC-9-6 and M-28-6-6) with differences in canopy architectures and growth durations at the Orinoca Ilanos. Agr For Meteor 116: 197-219

Solomon AM, Kirilenko AP (1997) Climate change and terrestrial biomass: what if trees do not migrate? Glob Ecol Biogeogr 6: 139-148

Srivastava A, Greppin G, Strasser RJ (1995) The steadystate chlorophyll a fluorescence exhibits in vivo an optimum as a function of light intensity which reflects the physiological state of the plant. Plant Cell Physiol 36: 839-848

Stampfli A, Zeiter M (2004) Plant regeneration directs changes in grassland composition after extreme drought: a 13-year study in southern Switzerland. J Ecol 92: 568-576

Tabaei-Aghdaei SR, Harrison P, Pearce RS (2000) Expression of dehydration-stress-related genes in the crowns of wheatgrass species (Lophopyrum elongatum (Host) A. Love and Agropyrum desertorum (Fisch. Ex Link. Schult) having contrasting acclimation to salt, cold and drought. Plant Cell Environ 23: 561-571

Tardieu F, Simonneau T (1998) Variability among species of stomatal control under fluctuating soil water status and evaporative demand: modeling isohydric and anisohydric behaviours. J Exp Bot 49: 419-432

Tuzet A, Perrier A, Leuning R (2003) A coupled model of stomatal conductance, photosynthesis and transpiration. Plant Cell Environ 26: 1097-1116

Van Peer L, Nijs I, Bogaert J, Verelst I, Reheul D (2001) Survival, gap formation, and recovery dynamics in grassland ecosystems exposed to heat extremes: the role of species richness. Ecosystems 4: 797-806

Van Peer L, Nijs I, Reheul D, De Cauwer B (2004) Species richness and susceptibility to heat and drought extremes in 
synthesized grassland ecosystems: compositional vs physiological effects. Funct Ecol 18: 769-778

Wagner D (1996) Scenarios of extreme temperature events. Climate Change 33: 385-407

Wang Z, Huang B (2004) Physiological recovery of Kentucky bluegrass from simultaneous drought and heat stress. Crop Sci 44: 1729-1736
White TA, Campbell BD, Kemp PD, Hunt CL (2000) Sensitivity of three grassland communities to simulated extreme temperature and rainfall events. Global Change Biol 6: 671-684

White TA, Campbell BD, Kemp PD, Hunt CL (2001) Impacts of extreme climatic events on competition during grassland invasions. Global Change Biol 7: 1-13 